\title{
A Prospective Study on the Feasibility, Safety, and Efficacy of a Modified Technique to Augment the Strength of Pedicle Screw in Osteoporotic Spine Fixation
}

\author{
Vikas Tandon, Kalyan Kumar Varma Kalidindi, Sandesh Pacha, Mohd Rafiq Bhat \\ Department of Spine Service, Indian Spinal Injuries Center, New Delhi, India
}

\begin{abstract}
Study Design: Prospective case study.
Purpose: Osteoporotic spine fixation by pedicle screw instrumentation is complicated by screw loosening, migration, or pullout with rates of up to $62 \%$ documented in the literature. Contemporary solutions have not adequately addressed these complications. We propose a modified surgical technique of cement augmentation with bicortical pedicle screw fixation to address the issue related to implant failure in osteoporotic spine.

Overview of Literature: Zindrick and his colleagues described a "windshield wiper" effect owing to the shift of center of rotation to the distal tip of the screw in the bicortical purchase of screws. An increase in pullout strength from $119 \%$ to $250 \%$ with polymethyl methacrylate augmentation has been documented in the literature. This technique has not been described in the literature.

Methods: A prospective study was conducted with 40 patients who underwent surgery by the modified technique. Intraoperative and postoperative complications directly related to the procedure were assessed. Improvement in pain and functional status were assessed. Follow-up radiographs were assessed to check for appreciable screw migration, loosening, or pullout.

Results: This technique was used in inserting 364 screws in 40 patients. We did not encounter any difficulty in inserting the screws. A total of 19 screws failed to breach the anterior cortex owing to an error in measurement. There were no complications during the procedure in any of the patients, and the postoperative period was uneventful. The mean follow-up period was 18 months. There were two patients in whom proximal junctional failure with kyphosis was noted during follow-up, who were surgically managed by extension of the fixation levels.

Conclusions: Bicortical fixation with cement augmentation is a technically feasible, safe, and effective technique to augment the strength of pedicle screws in osteoporotic spine fixation. It has the potential to be established as a standard of care in osteoporotic spine fixation.
\end{abstract}

Keywords: Osteoporosis surgery; Spine surgery; Pedicle screws; Bone cements; Surgical technique

Received Jun 28, 2019; Revised Aug 19, 2019; Accepted Sep 5, 2019

Corresponding author: Kalyan Kumar Varma Kalidindi

Department of Spine Service, Indian Spinal Injuries Center, Vasant Kunj, New Delhi, Delhi 110070, India

Tel: +91-9597732908, Fax: +91-011-42255225, E-mail: kalyanvarmambbs@gmail.com 


\section{Introduction}

The prevalence of osteoporosis, a common disease of the elderly, is on the rise owing to the rapidly increasing population worldwide. Moreover, the surgical indications for various spinal conditions have increased because of increased life expectancy, improved quality of life, and desire to remain physically active [1]. Hence, spine surgeons often encounter patients with an osteoporotic spine who require instrumentation. Pedicle screw fixation is the most commonly used method for stabilization of the vertebrae [2]. Common complications of instrumentation by pedicle screw fixation in an osteoporotic spine include screw loosening, migration, and pullout [3]. They usually result from micromotion or injuries or excess force applied at the bone-metal boundary [4]. Screw loosening rates of up to $62 \%$ for osteoporotic vertebra have been reported in the literature [5]. Various fixation techniques, including changes in screw design, changes in insertion technique, and use of bone cement, have been suggested to improve the fixation strength in the osteoporotic spine [6]. Bicortical fixation has been proposed as one such surgical technique to reduce screw loosening and pullout; however, it has the disadvantage of causing a windshield wiper effect, resulting in pedicle fracture or screw bending. Here, we describe a modified surgical technique of three-point fixation using polymethyl methacrylate (PMMA) augmentation and bicortical fixation to reduce the complications of implant failure and improve the effectiveness of osteoporotic spine fixation using pedicle screws. To the best of our knowledge, this technique has not been described in the literature to date.

\section{Materials and Methods}

A prospective study was conducted with 40 patients who visited our center from January 2017 to June 2017 with documented osteoporosis ( $\mathrm{T}$ score of $\leq-2.5$ on dual absorption X-ray absorptiometry scan according to the World Health Organization classification) and advised for surgery involving pedicle screw fixation for various indications. The characteristics of the patients are presented in Table 1. After obtaining written informed consent, they underwent surgery by the modified technique. Intraoperative and postoperative complications directly related to the procedure were assessed (Table 2). Improvement in pain and functional status were assessed.
Table 1. Characteristics of patients $(n=40)$

\begin{tabular}{lc} 
Characteristic & Value \\
Mean age (yr) & 72.2 \\
\hline $\begin{array}{l}\text { Gender } \\
\text { Male }\end{array}$ & 28 \\
\hline Female & 12 \\
\hline $\begin{array}{l}\text { Surgical indications } \\
\text { Osteoporotic fracture with back pain resistant to } \\
\quad \text { conservative treatment }\end{array}$ & 32 \\
\hline $\begin{array}{l}\text { Osteoporotic fracture with pain and neurologic } \\
\text { deficit }\end{array}$ & 6 \\
\hline $\begin{array}{l}\text { Symptomatic proximal junctional kyphosis after } \\
\text { surgical stabilization in osteoporotic spine }\end{array}$ & 2 \\
\hline $\begin{array}{l}\text { Location of screws } \\
\text { Thoracic }\end{array}$ & 184 \\
\hline $\begin{array}{l}\text { Thoracolumbar junction } \\
\text { Lumbar }\end{array}$ & 82 \\
\hline $\begin{array}{l}\text { Dual absorption X-ray absorptiometry scan range } \\
\text { (T-score) }\end{array}$ & 98 \\
\hline
\end{tabular}

Values are presented as mean, number of patients, or range.

Table 2. Perioperative and postoperative complications

\begin{tabular}{lc} 
Variable & \multicolumn{1}{l}{ Value } \\
Perioperative complications & \\
\hline Failure to hold anterior cortex & 19 Screws \\
\hline $\begin{array}{l}\text { Intraoperative cement leakage } \\
\text { (radiological) }\end{array}$ & 3 Screws (2 patients) \\
Cement leakage (clinical) & Nil \\
\hline Mortality (related to the procedure) & Nil \\
\hline Neurological complications & Nil \\
\hline Infection & Nil \\
\hline Postoperative complications & \\
\hline Infection & Nil \\
Screw loosening/migration/pullout & Nil \\
\hline Proximal junctional failure & 2 Patients \\
\hline
\end{tabular}

The patient was placed in a prone position. A posterior midline incision was made. Subperiosteal dissection was performed to expose the posterior bony elements. The entry point of the pedicle screw was identified by the intersection technique. Pedicle awl or burr was used to open the superficial cortex. A pedicle probe was used to navigate down the isthmus of the pedicle into the vertebral body under image guidance (Fig. 1, step 1). A pedicle sounding device was used to confirm the intraosseous trajectory of 
the probe. Care was taken not to breach the anterior cortex with the probe or sounding device. The depth of the track was measured, and an appropriate screw size was selected using the sounding device and an artery forceps, such that only $<2 \mathrm{~mm}$ of the screw crosses the anterior cortex of the vertebral body (Fig. 1, step 2). A bone-filling device was inserted into the prepared pedicle tract until it reached the middle one-third of the vertebral body. Before injection of the PMMA cement, air in the bone-filling device was sucked out with a $10-\mathrm{mL}$ syringe until the marrow blood filled the whole tract of the bone-filling device. When the consistency of the cement became similar to that of toothpaste, $3 \mathrm{~mL}$ of the cement for lumbar spine and 2-2.5

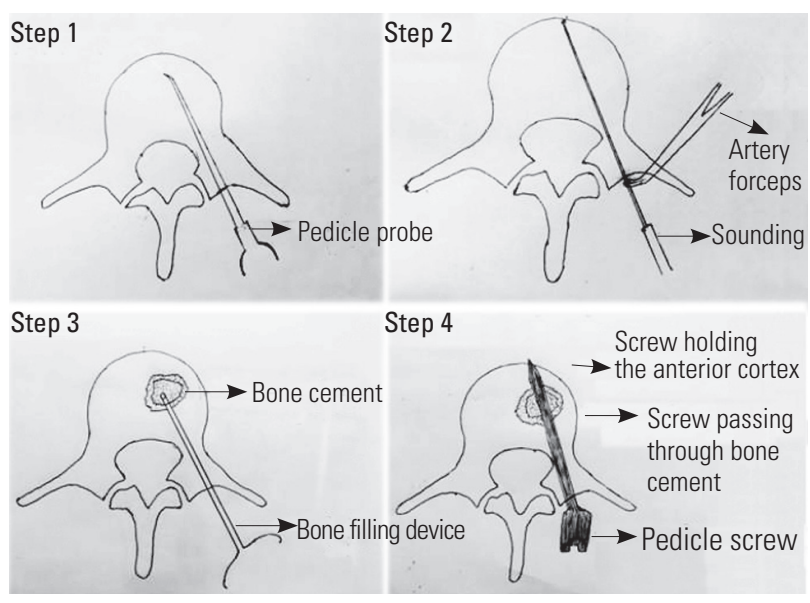

Fig. 1. Hand-drawn illustrations describing the modified technique of bicortical fixation with cement augmentation step-wise. Step 1: preparation of the screw tract using a pedicle probe; step 2: measurement of the depth of the track using a sounding device and an artery forceps; step 3: injection of cement using a bone-filling device; and step 4: insertion of pedicle screw such that it passes through the cement and holds the anterior cortex of the vertebral body.
$\mathrm{mL}$ of the cement for thoracic spine were injected into the bone-filling device (Fig. 1, step 3). Fluoroscopy was used to monitor the course of cement injection. After the cement injection, the bone-filling device was removed. An appropriately sized pedicle screw measured using the pedicle sounding device was immediately inserted into the pedicle track (Fig. 1, step 4). Care was also taken to direct the pedicle screw in an appropriate direction to prevent inadvertent injury to the aorta or vena cava owing to incorrect placement. Other techniques described to increase the hold of the pedicle screws such as more medial angulation and larger diameter screws were also employed in our patients. The commonly used screw length was $40-50 \mathrm{~mm}$, and the diameter was $5.5,6.5$, or $7.5 \mathrm{~mm}$. Four to eight pedicle screws were simultaneously inserted using a single pack of cement in majority of the patients.

Depending on the general condition of the patients, they were mobilized on the next day of the surgery. They were administered osteoporotic treatment according to the institute's protocol. Postoperative radiographs and computed tomography scans were performed to assess the screw position and cement leakage.

The patients were followed-up with radiographs at postoperative 3 months, 6 months, 1 year, and once every year thereafter. Follow-up radiographs were assessed to check for appreciable screw migration, loosening, or pullout. Visual Analog Scale (VAS) and Oswestry Disability Index (ODI) were measured pre- and postoperatively at 3 months, 6 months, 1 year, and once every year thereafter to assess the improvement in pain and functional disability, respectively.

This article does not contain any studies with human participants or animals performed by any of the authors.
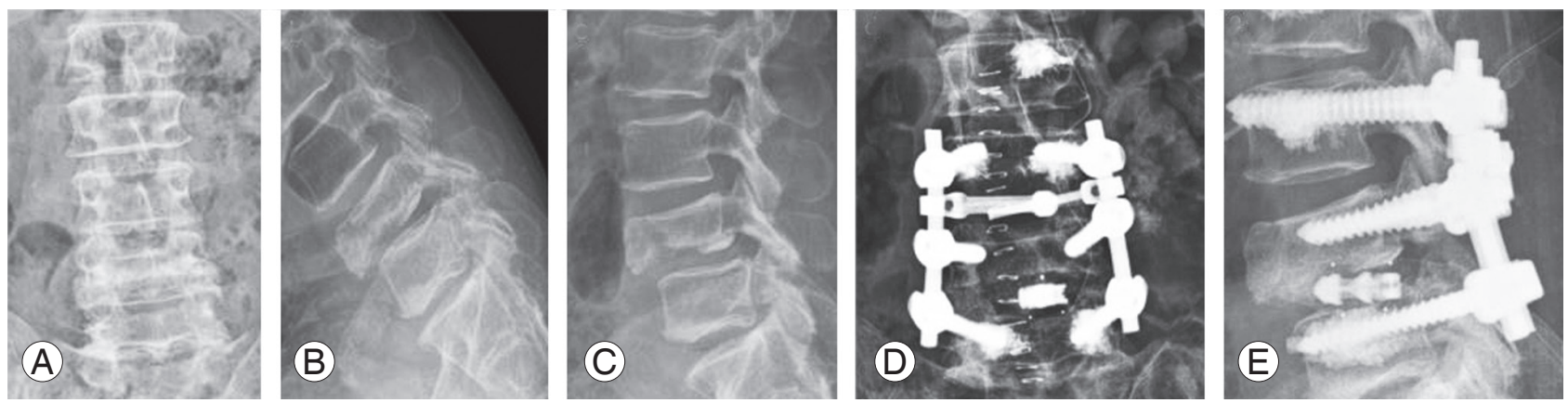

Fig. 2. Preoperative anteroposterior (A) and lateral flexion-extension radiographs (B, C) of a 76-year-old male with a history of fall showing an unstable fracture of $L 4$ vertebra. The patient was neurologically intact. There was a coronal split of the vertebral body with inferior endplate involvement. Bicortical screw fixation with cement augmentation was performed at L3 and L5 levels. Expandable cage was put in the L4-L5 disc space after disc preparation (D, E). 

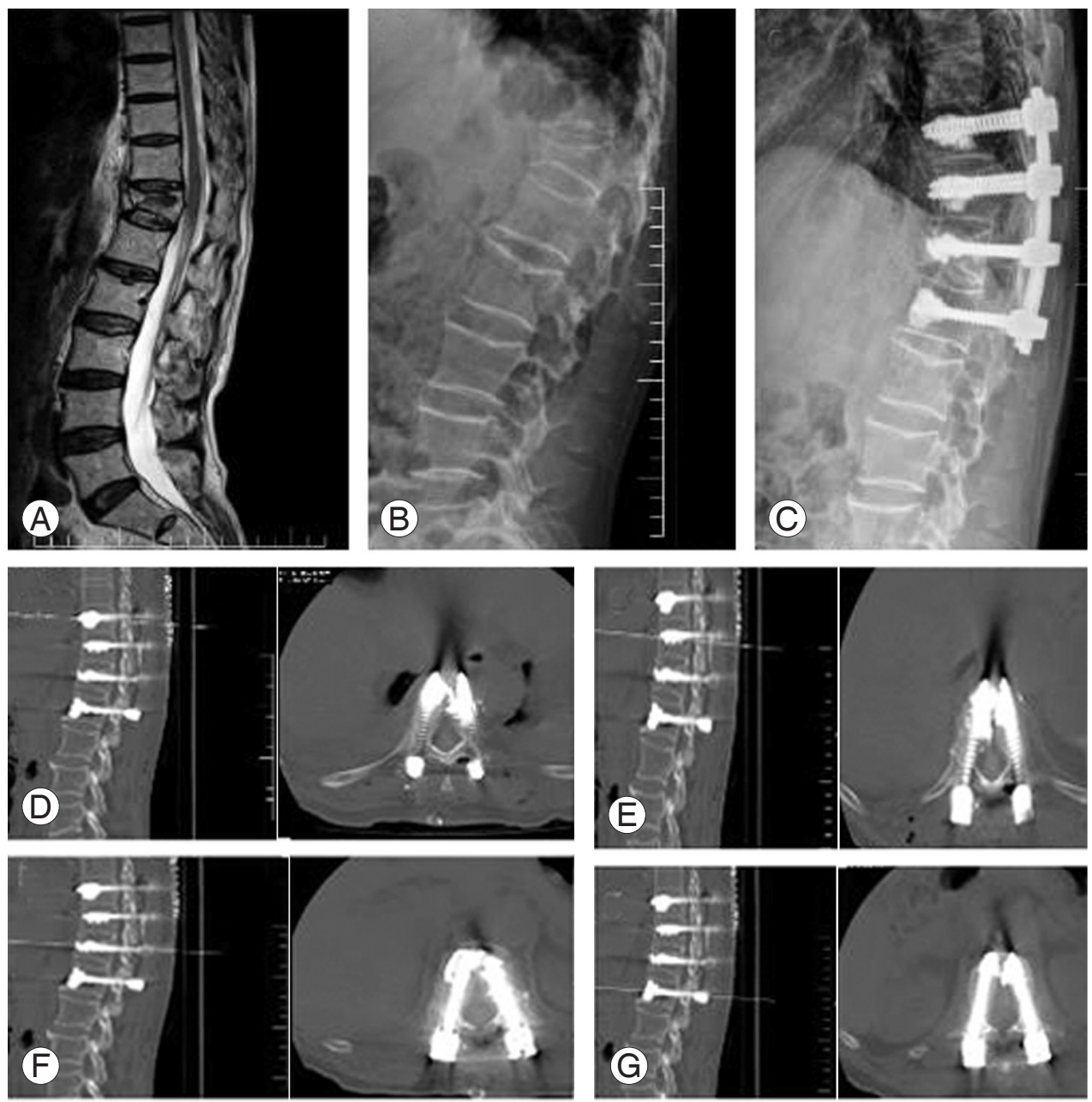

Fig. 3. (A) Sagittal T2 magnetic resonance imaging of a 75-year-old male who presented to us with severe back pain not responding to conservative management and showing an osteoporotic T12 fracture with marrow edema. His dual absorption X-ray absorptiometry scan suggested osteoporosis with $t$-value of -3.5 . (B, C) Preoperative and postoperative $X$-rays showing fracture fixation using the modified technique. (D-G) Computed tomography scan images showing bicortical fixation with cement in the vertebral body. Bicortical fixation could not be performed at the fractured vertebra.

\section{Results}

The modified technique has been utilized in inserting 364 screws in 40 patients. The illustrative cases are shown in Fig. 2 and Fig. 3. We did not encounter any difficulty in inserting the screws. However, 19 screws (three in the lumbar spine, two in the thoracolumbar junction, and 14 in the thoracic spine) failed to breach the anterior cortex owing to an error in the measurement or fracture pattern. We did not attempt a revision of those screws. There were no complications during the procedure in any of the patients. The postoperative period was uneventful in all patients. There was an evidence of cement leak anteriorly in two patients, but they were clinically asymptomatic
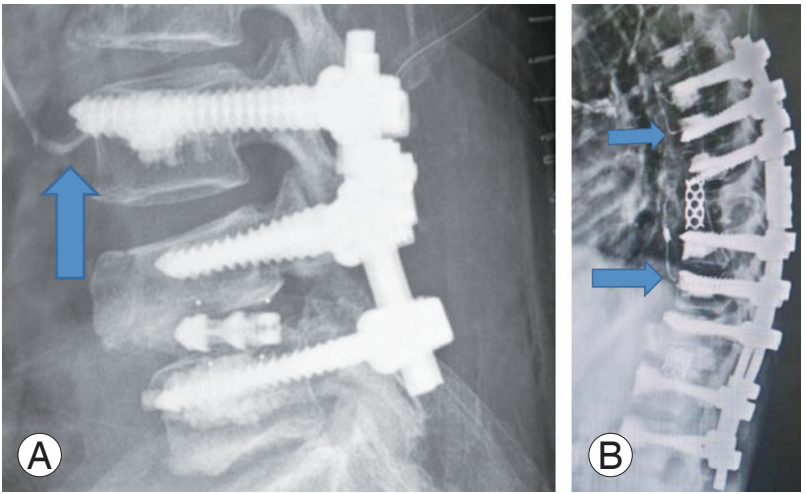

Fig. 4. (A, B) Postoperative X-rays of the two patients which showed cement leakage anteriorly (marked with blue arrows). 

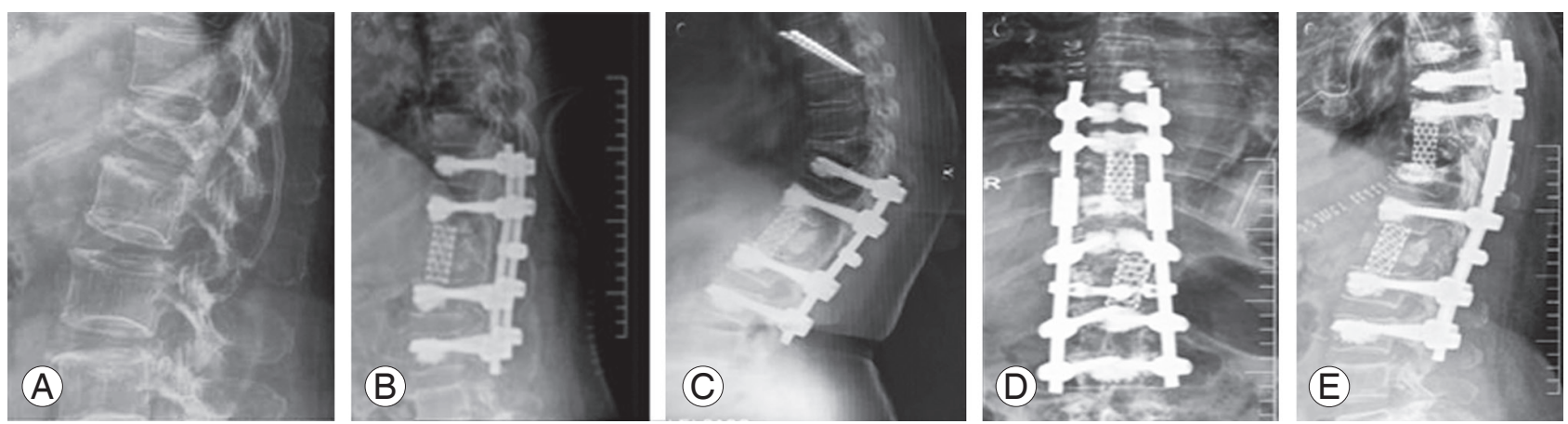

Fig. 5. A 65-year-old female presented to us with severe back pain and neurologic deficit after a history of trivial fall. X-rays suggested an osteoporotic $L 1$ fracture (A) for which bicortical cement-augmented fixation was performed from T11 to $L 3$ with corpectomy of the $L 1$ vertebra (B). (C) The postoperative follow-up X-rays showed a gradual collapse of the T10 vertebra with proximal junctional kyphosis. The proximal screws still held on to the vertebra without any evidence of loosening or pullout. (D, E) The patient was reoperated at 5 months after the first surgery by corpectomy and anterior reconstruction of T10 vertebra and bicortical cement-augmented screw fixation from T8.
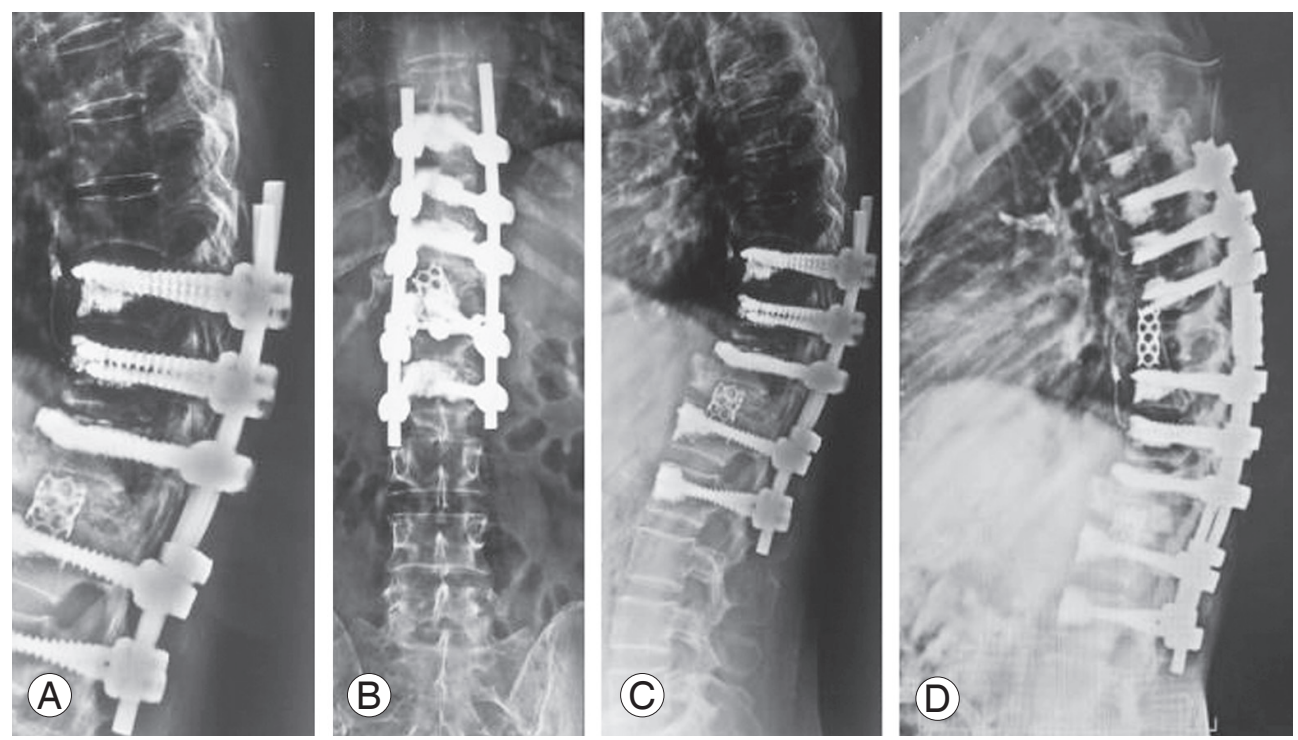

Fig. 6. A 61-year-old female presented to us with back pain and difficulty in walking. On examination, weakness was observed in both lower limbs, along with signs of myelopathy. (A) X-rays suggested an osteoporotic fracture of T11 and T12 for which corpectomy of T12 vertebra was performed with anterior cage reconstruction and pedicle screw fixation was performed from T9 to L2 using the modified technique. (B, C) She presented 2 months later with mid-back pain and radiation to the sides of the chest wall after a history of trivial fall. X-rays suggested proximal junctional kyphosis at T8 vertebra. (D) T8 corpectomy and anterior reconstruction were performed with the extension of instrumentation to T5 using the modified technique.

(Fig. 4). The VAS improved from 8.7 to 1.4 and ODI from $81.1 \%$ to $41 \%$ after the surgery. The mean follow-up period was 18 months. There was no appreciable screw loosening or migration in any of the patients on the follow-up radiographs. There were two patients in whom proximal junctional failure with kyphosis was observed during follow-up with symptoms of back pain. However, there was no screw loosening, pullout, or migration in those patients. They were surgically managed by extension of the fixation levels (Figs. 5, 6).

\section{Discussion}

The reported complications in the surgical management by instrumentation in an osteoporotic spine include pedicle and compression fractures, pseudarthroses with instrumentation failure, adjacent segment degeneration, and proximal junctional kyphosis [7]. Fusion in osteoporosis is delayed owing to reduced osteoblastic activity, poor vascularity, and lower bone marrow quality [8]. Hence, the implants utilized for temporary stabilization have to 
experience longer than usual period of stress. Moreover, the biomechanical properties of the osteoporotic bone contribute to early implant failure [9]. A number of surgical techniques and designs have been implemented in an attempt to improve the strength of the fixation between the pedicle screw and bone. Multiple levels of fixation, cement augmentation, bicortical purchase, hydroxyapatite coating, and the use of double screws are some of the described techniques used in osteoporotic spine fixation [9].

Cancellous bone is less dense and more profoundly affected in osteoporotic bone than in cortical bone [10]. Additionally, the cortex of the vertebral body is stronger than the cancellous bone in normal as well as osteoporotic bones [9]. Hence, a bicortical purchase would be stronger. An increase in pullout strength from $31 \%$ to $120 \%$ has been demonstrated with a bicortical screw when compared with a unicortical screw [11]. However, incorrect placement of bicortical screws has a risk of injury to major vascular structures [12]. Zindrick et al. [11] described a "windshield wiper" effect owing due to the shifting of the center of rotation to the distal tip of the screw in the bicortical purchase of screws, resulting in an increased risk of pedicle fracture or screw bending. We attempted to reduce this effect by utilizing bone cement as a separate anchor at the middle of the screw.

The technique of bone cement augmentation has been well-described in the literature [13,14]. PMMA is the most frequently used bone cement [15]. An increase in pullout strength from $119 \%$ to $250 \%$ has been documented in the literature with PMMA augmentation [16]. Hence, addition of PMMA augmentation to bicortical fixation would theoretically increase the strength of fixation than either alone. However, drawbacks with PMMA augmentation include exothermic thermal necrosis, inability to integrate in the surrounding bone, and difficulty in screw removal if necessary [17].

Some key points need to be emphasized in our modified technique. Extreme care should be taken to not penetrate the anterior cortex when using the pedicle probe and sounding device to prevent anterior migration of cement. The desired length of the pedicle screw should be accurately measured before cement injection using the sounding device and calibrated scale to prevent under- or overpenetration. We advise erring on the underside in case of any doubt to prevent untoward complications of overpenetration. The bone-filling device used for cement injection should be placed in the middle one-third of the vertebral body, and care should be taken to not penetrate the anterior cortex. The timing, amount, and viscosity of cement injection are also crucial. Based on the previous studies, we recommend injecting $3 \mathrm{~mL}$ of cement for the lumbar spine and 2-2.5 $\mathrm{mL}$ of cement for the thoracic spine when it has a toothpaste-like consistency and not to delay the pedicle screw insertion after cement injection [18].

Interesting findings of our study are the cases complicated by proximal junctional kyphosis. Although there was a biomechanical failure of the osteoporotic bone with collapse, the pedicle screws held on well, and there was no sign of loosening or pullout. This suggests that the hold of the screw was superior.

Theoretical advantages of the modified technique include an increase in pullout strength than either bicortical screw or PMMA augmentation alone. Furthermore, the windshield wiper effect in a bicortical purchase would be lessened with this technique. Our clinical study supported these theoretical advantages. This technique would not also add more to the cost of the procedure than the PMMA augmentation.

Theoretical risks associated with the technique include the risks of both bicortical fixation as well as PMMA augmentation. We did not encounter any implant-related complications in our study. However, accurate measurement of the screw length and timing of cement injection are crucial for successful implementation of the technique.

There are several limitations to this study. Here there was a lack of a comparative or control group. Thus, a larger series of patients with a long-term follow-up is required to establish the efficacy and safety of the procedure. Although the procedure has a superior pullout strength theoretically, a biomechanical analysis is still necessary to establish it.

\section{Conclusions}

Bicortical fixation with PMMA augmentation is a technically feasible, safe, and effective technique to augment the strength of the pedicle screws in osteoporotic spine fixation. It has a potential to be established as a standard of care in osteoporotic spine fixation.

\section{Conflict of Interest}

No potential conflict of interest relevant to this article was reported. 


\section{Acknowledgments}

The authors would like to thank the concerned patients for allowing the details to be shared.

\section{ORCID}

Kalyan Kumar Varma Kalidindi: https://orcid.org/00000002-4408-7035

\section{Author Contributions}

VT was involved in substantial contribution to the conception and design of the work. KKVK, SP, and MRB were involved in acquisition, analysis, or interpretation of data for the work. KKVK and SP were also involved in the drafting of the work.

\section{References}

1. Chin DK, Park JY, Yoon YS, et al. Prevalence of osteoporosis in patients requiring spine surgery: incidence and significance of osteoporosis in spine disease. Osteoporos Int 2007;18:1219-24.

2. Teng H, Zhou Y, Wang J. Research progress in application of vertebral pedicle screw augmentation in treating osteoporotic spine. Chin J Trauma 2005;21:392-4.

3. Halvorson TL, Kelley LA, Thomas KA, Whitecloud TS 3rd, Cook SD. Effects of bone mineral density on pedicle screw fixation. Spine (Phila Pa 1976) 1994;19:2415-20.

4. Hu SS. Internal fixation in the osteoporotic spine. Spine (Phila Pa 1976) 1997;22(24 Suppl):43S-48S.

5. El Saman A, Meier S, Sander A, Kelm A, Marzi I, Laurer $\mathrm{H}$. Reduced loosening rate and loss of correction following posterior stabilization with or without PMMA augmentation of pedicle screws in vertebral fractures in the elderly. Eur J Trauma Emerg Surg 2013;39:455-60.

6. Shea TM, Laun J, Gonzalez-Blohm SA, et al. Designs and techniques that improve the pullout strength of pedicle screws in osteoporotic vertebrae: current status. Biomed Res Int 2014;2014:748393.
7. DeWald CJ, Stanley T. Instrumentation-related complications of multilevel fusions for adult spinal deformity patients over age 65: surgical considerations and treatment options in patients with poor bone quality. Spine (Phila Pa 1976) 2006;31(19 Suppl):S144-51.

8. Park SB, Chung CK. Strategies of spinal fusion on osteoporotic spine. J Korean Neurosurg Soc 2011;49:317-22.

9. Ponnusamy KE, Iyer S, Gupta G, Khanna AJ. Instrumentation of the osteoporotic spine: biomechanical and clinical considerations. Spine J 2011;11:54-63.

10. Li HM, Zhang RJ, Gao H, et al. Biomechanical fixation properties of the cortical bone trajectory in the osteoporotic lumbar spine. World Neurosurg 2018;119:e717-27.

11. Zindrick MR, Wiltse LL, Widell EH, et al. A biomechanical study of intrapeduncular screw fixation in the lumbosacral spine. Clin Orthop Relat Res 1986;(203):99-112.

12. Weinstein JN, Rydevik BL, Rauschning W. Anatomic and technical considerations of pedicle screw fixation. Clin Orthop Relat Res 1992;(284):34-46.

13. Bostrom MP, Lane JM. Future directions: augmentation of osteoporotic vertebral bodies. Spine (Phila Pa 1976) 1997;22(24 Suppl):38S-42S.

14. Sarzier JS, Evans AJ, Cahill DW. Increased pedicle screw pullout strength with vertebroplasty augmentation in osteoporotic spines. J Neurosurg 2002;96(3 Suppl):309-12.

15. Hickerson LE, Owen JR, Wayne JS, Tuten HR. Calcium triglyceride versus polymethylmethacrylate augmentation: a biomechanical analysis of pullout strength. Spine Deform 2013;1:10-5.

16. Burval DJ, McLain RF, Milks R, Inceoglu S. Primary pedicle screw augmentation in osteoporotic lumbar vertebrae: biomechanical analysis of pedicle fixation strength. Spine (Phila Pa 1976) 2007;32:1077-83.

17. Lieberman IH, Togawa D, Kayanja MM. Vertebroplasty and kyphoplasty: filler materials. Spine J 2005;5(6 Suppl):305S-16S.

18. Chang MC, Liu CL, Chen TH. Polymethylmethacrylate augmentation of pedicle screw for osteoporotic spinal surgery: a novel technique. Spine (Phila Pa 1976) 2008;33:E317-24. 